
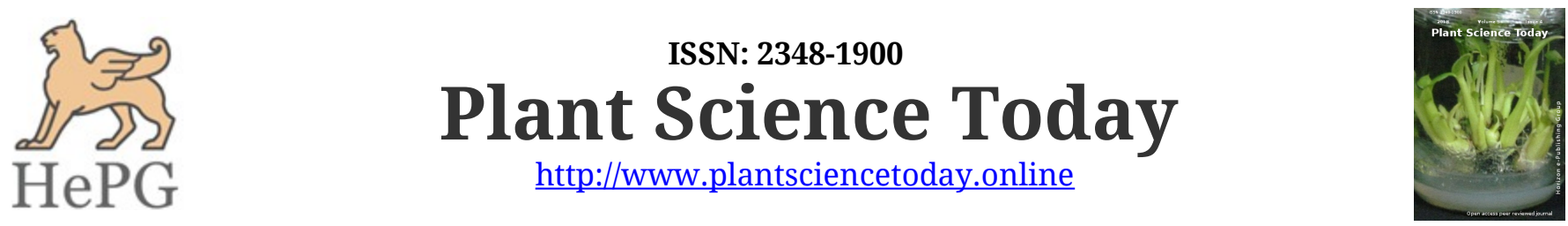

OPEN ACCESS

Research Article

\title{
Effects of soil early-spring temperature on the morphometric parameters of mitochondria in Galanthus nivalis L. leaves
}

\author{
*O.M. Fediuk, N.O. Bilyavska, E.K. Zolotareva
}

Department of Phytochemistry and Membranology, M.G. Kholodny Institute of Botany, Kyiv, Ukraine

\section{Article history}

Received: 24 June 2018

Accepted: 13 September 2018

Published: 02 October 2018

\section{Editor}

Dr. Aicha Belkadhi, University of Tunis El Manar, Tunisia

\section{Publisher}

Horizon e-Publishing Group

\author{
*Correspondence \\ O.M. Fediuk \\ $凶$ olgamuronivna@ukr.net
}

\begin{abstract}
In the natural conditions early-spring period development of Galanthus nivalis L., the leaves germination from bulbs was carried out in the soil surface layer, mainly, covered with snow, so the leaves were exposed to low soil temperatures. It was found, that at the leaf germination stage, when exposed to minus soil temperature, the mitochondria were predominantly elongated, that is, functionally active. Under the influence of positive temperature, the mitochondria form changed to a round one, which indicates their transition to low functional activity. A similar tendency was manifested even during the budding stage, in particular, when the soil temperature was lowered to an average of $3.47^{\circ} \mathrm{C}$, the mitochondria changed their form to an elongated one, that is, they passed into an active functional state. Wherein, the temperature of the leaves was higher by $3.84{ }^{\circ} \mathrm{C}$ compared to the soil. At the stages of germination and budding of $G$. nivalis under natural conditions, a direct correlation was found between the soil surface layer temperature and the leaves temperature, and at the flowering stage this relation was reverse. During the flowering stage, despite the influence of predominantly positive soil temperatures, leaves growth was significantly slowed, and their temperature was only slightly higher by $0.38{ }^{\circ} \mathrm{C}$ compared to the soil. At the same time, the mitochondria changed their shape to a round one. Thus, the increase in their long axis at different stages in spring development, are aimed at adapting to influence low temperatures of the soil surface layer.
\end{abstract}

\section{Keywords}

Galanthus nivalis; mitochondria; electron microscopy; morphometry; thermometry

\section{Citation}

Fediuk OM, Bilyavska NO, Zolotareva EK. Effects of soil early-spring temperature on the morphometric parameters of mitochondria in Galanthus nivalis L. leaves. Plant Science Today 2018;5(4):149-154. https://dx.doi.org/10.14719/pst.2018.5.4.405

Copyright: (C) Fediuk et al. (2018). This is an open-access article distributed under the terms of the Creative Commons Attribution License, which permits unrestricted use, distribution, and reproduction in any medium, provided the original author and source are credited (https://creativecommons.org/licenses/by/4.0/).

\section{Introduction}

The development of ephemeroid plants in the early spring, in the natural conditions of a temperate continental climate, carried out in influenced by significant fluctuations of abiotic factors. Among them, the soil temperature, as compared with the air temperature, changes more slowly in the natural environment, since in early-spring conditions, frozen and snow-covered soil cannot warm up with sunlight as quickly as atmospheric air. Numerous studies have been devoted to understanding the effects of low positive temperatures on the development of plants (1-3). 
The results of the studies showed that this abiotic factor was able to change not only the morphometric indices (4) but also the functional activity of mitochondria $(5,6)$ and chloroplasts (7). At the same time, the impact of soil temperature on the structural components of the supramolecular energetic complex of plant leaves in the natural environment, in particular, on the form of the mitochondria in leaf mesophyll cells of the spring ephemeroid Galanthus nivalis L., remains undiscovered under the natural conditions.

Among cellular organelles, which are components of the energetic complex of plant leaves, the mitochondria performs an important function of energy transformation. The mitochondrial respiratory chain converts metabolic energy into an electrochemical proton gradient across the inner mitochondrial membrane; this potential gradient is then utilized by the F1F0 ATP synthase, the molecular machine that generates ATP from ADP and phosphate by rotary catalysis (8). Plant mitochondria link the cellular processes of carbon and nitrogen metabolism through the tricarboxylic acid cycle and the photorespiratory cycle (9). In addition, the mitochondria are involved in the active transport of ions; they are capable of ions accumulation such as $\mathrm{K}^{+}, \mathrm{Ca}^{2+}, \mathrm{Mg}^{2+}, \mathrm{Mn}^{2+}, \mathrm{HPO}_{4}{ }^{2-}$ and active homeostatic regulation of the ionic composition in the hyaloplasm (10). It is probable that the processes of energy conversion are accompanied by characteristic changes in the forms and volume of mitochondria under hypothermal conditions. If such changes in quantitative indices of the mitochondria under hypothermal conditions enable the survival of cells, we can consider it as adaptive adjustments that are needed for cold tolerance.

It has been shown that the mitochondria of cold-tolerant plants are able to change their shape and avoid damages in their cristae under the influence of low atmospheric air temperatures $(11,12)$. However, effects at low soil temperatures are not well documented. We assume that under the hypothermal natural conditions, soil temperature can significantly affect the structural parameters of the mitochondria in the leaves of $G$. nivalis, since the leaves are located at a small distance from the surface of the soil.

Taking into account the above, we focus on the adaptive changes in the mesophyll mitochondria of $G$. nivalis leaves grown in natural environment where in the early spring the influence of the temperature of the surface soil layer during the stages of germination, budding and flowering of the plants occurs.

\section{Materials and methods}

The leaves of $G$. nivalis plants that grew in natural conditions in the open ground of the Mokvinski forestry (Kostopil district, Rivne region, Ukraine) were used in this study. Climatic conditions within the forestry are characterized by a predominance of average air temperatures $-4.8^{\circ} \mathrm{C}$ in January and $18.1^{\circ} \mathrm{C}$ in May (for the period from 2012 to 2018). The relief of the area is mostly flat, without significant hills and depressions. The surface layer is formed with the predominance of gray-forest and dark-gray soils.

The study of temperature dynamics of $G$. nivalis leaves was carried out under natural conditions, without the removal of plants from the soil during germination, budding and flowering. The temperature of the surface of the leaves and the surface layer of soil was measured by the Thermograph Fluke 105 Thermography (USA) equipped with an infrared camera. The thermal (within the spectrum of 7.5-13 $\mu \mathrm{m}$ ) radiation of the investigated objects was detected using this camera. On the received photographs, measuring points with digital values of their temperatures were displayed. The features of the distribution of temperature values of the objects under investigation were determined by the color of the points (and the corresponding pixels). The range of temperatures that the camera can fix is from -10 to $250^{\circ} \mathrm{C}$. Possible influence of the temperature of the surface soil layer on the temperature of leaves of $G$. nivalis was estimated by comparing the values of these indices by means of mathematical methods of variation statistics.

For ultrastructural analysis of mitochondria, fragments were removed from the middle part of the leaves in the size of $2 \times 2$ $\mathrm{mm}$. The preliminary fixation of the material was carried out at room temperature $\left(18-22^{\circ} \mathrm{C}\right)$ by vacuum infiltration of specimens in $2.5 \%$ glutaraldehyde in $0.1 \mathrm{M}$ phosphate buffer (pH 7.2) and then for 8 hours at $4{ }^{\circ} \mathrm{C}$. The specimens were then washed with buffer $(2 \times 20 \mathrm{~min})$ and transferred to $1 \% \mathrm{OsO}_{4}$ in $0.1 \mathrm{M}$ cacodylate buffer, $\mathrm{pH} 7.2$, at $4{ }^{\circ} \mathrm{C}$ overnight. The preparations were dehydrated in ethanol and propylene oxide series. The samples were then infiltrated with a mixture of epone-araldite epoxy resin and propylene oxide and a clean resin, after which the specimens were transferred to the thermostat for polymerization at 37 and $60{ }^{\circ} \mathrm{C}$. Ultra-thin sections were made on ultramicrotome LKB-V (LKB, Sweden) and stained with lead citrate. The sections were examined in a transmission electronic microscope JEM-1300 (JEOL, Japan) (13).

The study of morphometric indices of the mesophyll mitochondria of $G$. nivalis leaves was performed on its photographic images, which were obtained by methods of transmission electron microscopy. On photographic images of mitochondria, measurements of the size, length and short axis of mitochondria on its sections were carried out using ImageJ program (NIH, USA). Microphotos of 30 mitochondria were analyzed for each stage of leaf development. 
Table 1. Influence of soil surface layer temperature on $G$. nivalis leaf temperature and mean sizes of cell mesophyll mitochondria in the natural environment during early-spring period

\begin{tabular}{lccc}
\hline \multicolumn{1}{c}{ Parameters } & \multicolumn{2}{c}{ Development Stage } \\
\cline { 2 - 4 } & Germination & Budding & Flowering \\
\hline Temperature of surface soil layer, ${ }^{\circ} \mathrm{C}$ & $4.03 \pm 0.257$ & $5.40 \pm 0.616$ & $11.73 \pm 0.671$ \\
\hline Leaves temperature, ${ }^{\circ} \mathrm{C}$ & $5.51 \pm 0.604$ & $9.24 \pm 0.845$ & $11.34 \pm 0.469$ \\
\hline Mitochondria length, $\mu$ & $0.980 \pm 0.005$ & $1.663 \pm 0.003$ & $0.718 \pm 0.008$ \\
\hline Mitochondria width, $\mu$ & $0.785 \pm 0.006$ & $0.466 \pm 0.002$ & $0.573 \pm 0.003$ \\
\hline Mitochondria perimeter, $\mu$ & $2.789 \pm 0.003$ & $3.736 \pm 0.006$ & $2.036 \pm 0.012$ \\
\hline Mitochondria area, $\mu^{2}$ & $0.586 \pm 0.012$ & $0.593 \pm 0.027$ & $0.311 \pm 0.025$ \\
\hline Values represent the $m^{2}$ & & \\
\hline
\end{tabular}

Values represent the mean of four to six replicate plants ( \pm SE).

The sizes of mitochondria were processed using the methods of variation statistics. The difference between the average values of the indices was calculated using Student's t-test. Differences were considered statistically significant at $P \leq 0.05$.

\section{Results and discussion}

In early spring, germination of leaves occurs from the bulbs of the ephemeroid G. nivalis, which are in the surface layer of soil, so they are under a significant influence of soil temperature. During the stages of germination and flowering, the mean value of the temperature of the soil surface in the immediate vicinity of the plants varied from 4.03 to $11.73^{\circ} \mathrm{C}$, whereas the temperature of the leaves of plants changed from 5.51 to 11.34 (Table 1).

The stage of germination occurred at a minimum average soil surface layer temperature of $4.03{ }^{\circ} \mathrm{C}$, the temperature of the leaves was higher by 1.4 times (Figs. 1A, 1B). In the absence of stress conditions and under the influence of positive soil temperatures, the mitochondria in the sections had a rounded form. The length of their short axis was 1.2 times smaller compared with a long axis. The rounded form of mitochondria and non-contrast cristae (Fig. 1C) can indicate a low functional activity of mitochondria during the germination stage. Therefore, their division (see Fig. 1C) for increasing the overall population of mitochondria is probably related to the preparation for further synthesis of substances that are necessary for the growth and development of plants.

In publications, devoted to the study adaptation mechanisms of plants to the influence low temperatures of atmospheric air, the authors attention is mainly drawn to the ability of flower nectaries (14) and leaf plastids to adapts to the influence of hypothermic environmental conditions (15). It was reported, that Symplocarpus foetidus (16) at the stage of pollination maintains a flower at constant temperature, regardless of the ambient air temperature. The flowers of Helicodieros muscivorus (17), provide the necessary temperature for pollination by releasing thermal energy. Wherein, remain insufficiently disclosed the peculiar properties of the earlyspring ephemeroids adaptive mechanisms, that develop in the vicinity of the frozen soil top layer.

The results of our studies on leaves of early-spring ephemerides of $G$. nivalis showed, that at the stage budding of $G$. nivalis plants, the average value temperatures of the soil surface layer, was 1.3 times higher than in the previous stage (see Table 1), and the leaves temperature exceeded the soil temperature by 1.7 times (Fig. 1D, 1E). Wherein, the mitochondria heaved an elongated shape with membranes contrasting contours (Fig. 1F), which indicates their functional activity. Such an increase in the functional activity of mitochondria at stages prior to flowering is consistent with the results of our previous studies (18) and points to the activation of energy processes associated with leaves adaptation to a low $\left(-3.47^{\circ} \mathrm{C}\right)$ soil surface temperature, that have been registered at the budding stage.

The appearance of morphometric changes, due to the low temperatures influence, is also characteristic for Antarctic plants. In particular, the appearance of outgrowths and depressions in leaves plastids is also considered as adaptation to extreme conditions $(14,19,20)$.

During the flowering stage, the mean values of the soil surface layer temperature were 2.2 times higher than at the previous stage (see Table 1), while the temperature of the leaves practically did not differ from the soil temperature, in particular, it was only 1.03 times lower (Fig. 1G, 1H). Under these conditions, the functional activity of the mitochondria was low, which is confirmed by their round shape and noncontrasting cristae (Fig. 1I). Therefore, the average soil temperature of $11.73{ }^{\circ} \mathrm{C}$ can be considered unstable, but optimal for $G$. nivalis leaves, since 

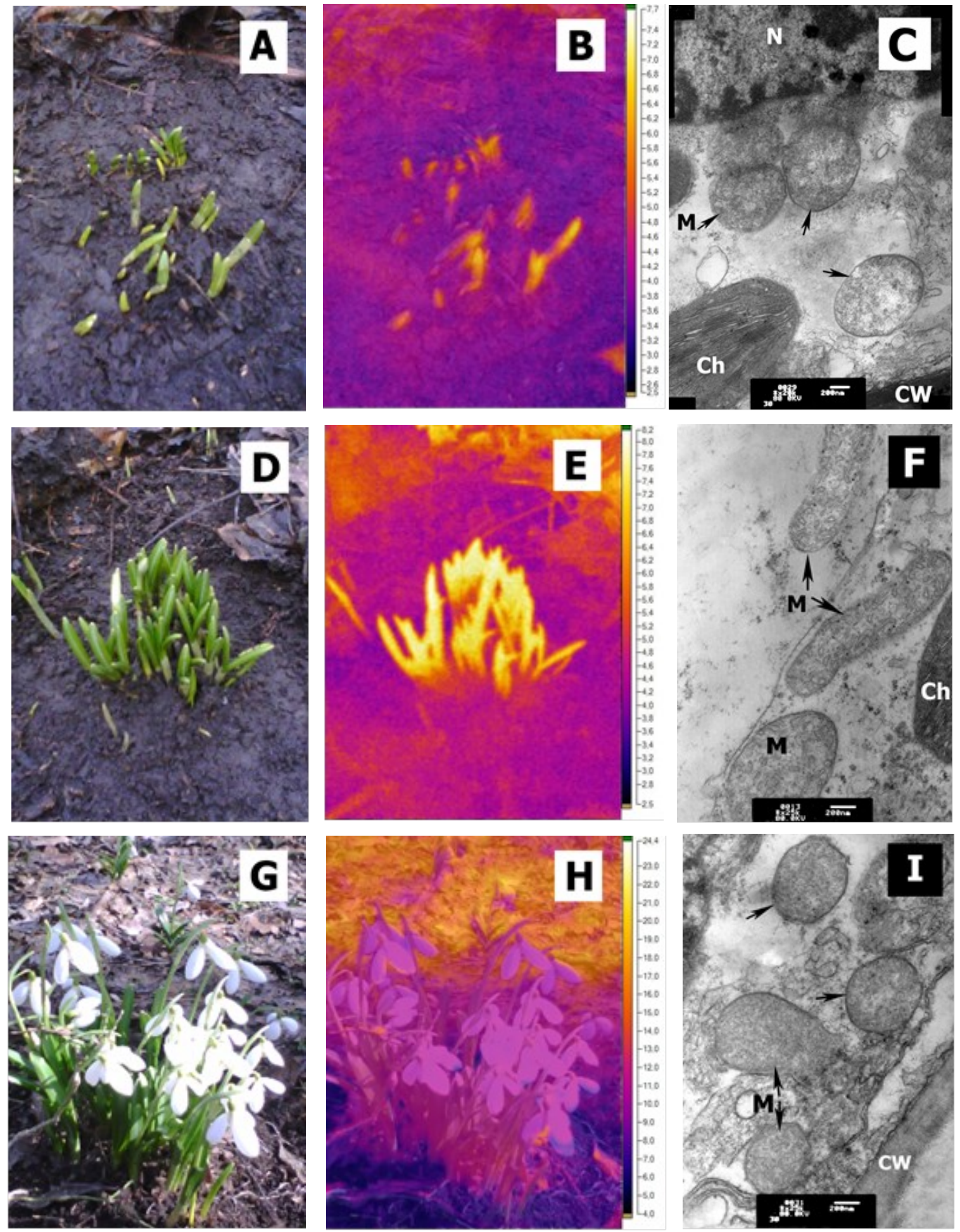

Fig. 1. Photographic (A, D, G), thermographic (B, E, H) leaf images and electron microscopic Scale bar = $200 \mathrm{~nm}(\mathrm{C}, \mathrm{F}, \mathrm{I})$ images of $G$. nivalis mitochondria at stages of germination (A, B, C), budding (D, E, F) and flowering (G, H, I).

Abbreviations: $\mathrm{Ch}$ - chloroplast, $\mathrm{CW}$ - cell wall, $\mathrm{M}$ - mitochondria, $\mathrm{N}$ - nucleus and arrow - divided mitochondria.

the adaptive mechanism for leaf temperature increase was not activated in the absence of stress.

The relationship of probability between the temperature of the soil surface layer and the temperature of leaves of $G$. nivalis under natural conditions is quite high. In particular, in the general data sampling, such a relationship was direct with corresponding correlation coefficients (r) of 0.88 and 0.73 at $\mathrm{P}<0.05$ at the germination and budding stages, respectively, while this ratio turned out to be the inverse of the coefficient of $-0.86(\mathrm{P}<0.05)$ at the flowering stage.

Thus, in the spring period of development G. nivalis, under the influence of minus soil temperatures, the mitochondria morphometric changes are carried out, in particular, the elongation of their forms and, accordingly, the transition to functional activity. Under the 
influence of plus temperatures, more favourable for the leaves development, the mitochondria shape changed to a rounded one and their number increased due to active division. Since these leaves are morphologically successfully developed under the influence of minuses and plus temperatures, such morphometric changes are adaptive.

\section{Conclusion}

Thus, the study showed that under natural conditions of early-spring development $G$. nivalis, at the stage germination leaf, the influence of negative soil temperatures led to an increase in the size of long axis of mitochondria and the formation of an elongated shape corresponding to the active functional state. The influence of positive soil temperatures, more favourable for development, was manifested in a change to long form of mitochondria on to a rounded one, that is, a decrease in the functional activity of each of them. But at the same time, through active division of mitochondria, and correspondingly an increase in their number, the level of functional activity necessary for development was provided.

At the budding stage, a short-time decrease in soil temperature on average to $-3.47{ }^{\circ} \mathrm{C}$ caused the elongation of the mitochondrial form and, correspondingly, an increase in their functional activity, adaptive mechanisms stimulation for increasing the leaves temperature. At this, leaves temperature by $3.84{ }^{\circ} \mathrm{C}$ higher than that of the soil. At the flowering stage, in the absence of influence of low soil temperatures, the intensity of leaves growth decreased and the difference between the average temperature of leaves and the soil surface layer was minimal $\left(0.38{ }^{\circ} \mathrm{C}\right)$. The changes in the early-spring values temperature soil led to the formation of rounded and elongated mitochondria forms and corresponding changes in their functional activity, aimed at adapting to the effects of hypothermal conditions.

\section{Acknowledgements}

The authors are thankful to the workers of the state enterprise "Kostopil forestry", Kostopil district of the Rivne region (Ukraine), for the assistance provided in collecting plant material.

\section{Conflict of interest}

The authors declare no conflict of interest.

\section{Authors' contribution}

All authors jointly formed the concept and design, to planned and conducted experiments, developed of methodology, acquisition of data, analyzed and interpreted of data, wrote, viewed and revised the manuscript.

\section{References}

1. Stefanowska M, Kuraś M, Kacperska A. Low Temperature-induced Modifications in Cell Ultrastructure and Localization of Phenolics in Winter Oilseed Rape (Brassica napus L. var. oleifera L.) Leaves. Ann Bot. 2002;90(5):637-45. https://doi.org/10.1093/aob/mcf241

2. Buchner O, Holzinger A, Lütz C. Effects of temperature and light on the formation of chloroplast protrusions in leaf mesophyll cells of high alpine plants. Plant, Cell Environ. 2007; $\quad 30(11): \quad$ 1347-56. https://doi.org/10.1111/j.1365-3040.2007.01707.x

3. Du YY, Chen H, Zhong WL, Wu LY, Ye JH, Lin C, et al. Effect of temperature on accumulation of chlorophylls and leaf ultrastructure of low temperature induced albino tea plant. African J Biotechnol. 2008; 7(12):18815. https://doi.org/10.5897/AJB2008.000-5036

4. Giełwanowska I, Pastorczyk M, Kellmann-Sopyła W, Górniak D, Górecki RJ. Morphological and Ultrastructural Changes of Organelles in Leaf Mesophyll Cells of the Arctic and Antarctic Plants of Poaceae Family Under Cold Influence. Arctic, Antarct Alp Res. 2015; http://dx.doi.org/10.1657/AAAR0014-019 47(1):17-25

5. Klymchuk DO, Kosakivska I V, Akimov YM, Shcherbatyuk MM, Vorobyova T V. Structure-functional Peculiarities of Brassica campestris and Amarantus caudathus leave cells under low positive temperature. Bull of Kharkiv National Agrarian Univ. Ser Biol. 2011;3(24):15-24.

6. Heidarvand L, Millar AH, Taylor NL. Responses of the Mitochondrial Respiratory System to Low Temperature in Plants. CRC Crit Rev Plant Sci. 2017;36(4):217-40. https://doi.org/10.1080/07352689.2017.1375836

7. Liu ZG, Sun WC, Zhao YN, Li XC, Fang Y, Wu JY, et al. Effects of Low Nocturnal Temperature on Photosynthetic Characteristics and Chloroplast Ultrastructure of Winter Rapeseed. Russ J Plant Physiol. 2016; https://doi.org/10.1134/S1021443716040099 63(4):451-60.

8. Strauss M, Hofhaus G, Schröder RR, Kühlbrandt W. Dimer ribbons of ATP synthase shape the inner mitochondrial membrane. EMBO J. 2008;27(7):1154-60. https://doi.org/10.1038/emboj.2008.35

9. Taylor NL, Day DA, Millar AH. Targets of stress-induced oxidative damage in plant mitochondria and their impact on cell carbon/nitrogen metabolism. J Exp Bot. 2004; https://doi.org/10.1093/jxb/erh001 55(394):1-10.

10. Lehninger AL. The Mitochondrion: Molecular Basis of Structure and Function [Internet]. New YorkAmsterdam: Verlag W. A. Benjamin, Inc.; 1964. 316 p. https://onlinelibrary.wiley.com/doi/abs/10.1002/ange.196 $\underline{50770829}$

11. Yu J, Cang J, Zhou Z, Liu L. Anatomical Structure Comparison Between Leaves of Two Winter Wheat Cultivars with Different Cold/Freezing Tolerance Under Low Temperature Stress. J Northeast Agric Univ. 2011;18(3):1-6.

https://doi.org/10.1016/S1006-8104(13)60091-4

12. Vella NGF, Joss T V, Roberts TH. Chilling-induced ultrastructural changes to mesophyll cells of Arabidopsis grown under short days are almost completely reversible by plant re-warming. Protoplasma. $2012 ; \quad$ 249(4):1137-49. https://doi.org/10.1007/s00709-011-0363-5 
13. Fediuk OM, Bilyavska NO, Zolotareva OK. Effects of sucrose on structure and functioning of photosynthetic apparatus of Galanthus nivalis L. leaves exposed to chilling stress. Ann RSCB. 2017;XXI(3):43-51. https://doi.org/10.ANN/RSCB-2018-0002:RSCB

14. Weryszko-Chmielewska E, Chwil M. Flowering biology and structure of floral nectaries in Galanthus nivalis L. Acta Soc. Bot. Pol. 2016;85(1):1-20. https://doi.org/10.5586/asbp.3486

15. Scepankova I, Hudák J. Leaf and tepal anatomy, plastid ultrastructure and chlorophyll content in Galanthus nivalis L. and Leucojum aestivum L. Plant Syst Evol. 2004 Jan 23; 243(3-4):211-9. https://doi.org/10.1007/s00606-003-0086-y

16. Seymour RS. Dynamics and precision of thermoregulatory responses of eastern skunk cabbage Symplocarpus foetidus. Plant, Cell Environ. 2004 Aug 1; 27(8):1014-22.

http://doi.wiley.com/10.1111/j.1365-3040.2004.01206.x
17. Seymour RS, Gibernau M, Ito K. Thermogenesis and respiration of inflorescences of the dead horse arum Helicodiceros muscivorus, a pseudo-thermoregulatory aroid associated with fly pollination. Funct Ecol. 2003 Dec 1 ;

17(6):886-94. http://doi.wiley.com/10.1111/j.1365-2435.2003.00802.x

18. Fediuk OM, Bilyavska NO. Ultrastructural changes in Galanthus nivalis L. foliar mitochondria at vegetation in hypothermal conditions. Bull of Kharkiv National Agrarian Univ. Ser Biol. 2015;2(35):58-63.

19. Giełwanowska I, Szczuka E, Bednara J, Górecki R. Anatomical features and ultrastructure of Deschampsia antarctica (Poaceae) leaves from different growing habitats. Ann Bot. 2005 Nov 1;96(6):1109-19. https://doi.org/10.1093/aob/mci262

20. Gielwanowska I, Szczuka E. New ultrastructural features of organelles in leaf cells of Deschampsia antarctica Desv. Polar Biol. 2005 Nov 1;28(12):951-5. https://doi.org/10.1007/s00300-005-0024-2 